\title{
Editorial: Prospects for 2006
}

By the time you read this Editorial, 2006 will be with us and another year will have passed by. So what is the outlook for 2006? and what does this mean for the revenue management and pricing community? My top ten predictions are in reverse order:

10. The emergence of revenue management in the advertising industry will take hold as the variable RPS (revenue per second) wins. Media companies will have access to more finely tuned targeting methods that segment out audiences based upon the most important variables. These new methods will help advertisers and publishers to identify and influence audiences more effectively and efficiently.

9. Revenue management will focus on developing forecasting models that account for behavioural, demographic and geographic methods to generate better forecasts across niche markets.

8. Performance-based pricing models will demonstrate the true value of search engine marketing (SEM) as the lead generation channel. These SEM tools will understand the market price of advertising and the true added value to the advertiser.

7. Tesco's club card will be the ultimate in dynamic packing propositions. Tesco's can now predict that when customers buy ice cream they also want pasta. Therefore packaging ice cream and pasta becomes so simple. Tesco's can now offer the ultimate personal dynamic packages for their customers.
6. Brands will lose out as consumers increasingly select products based upon price. Flights offered by American Airlines are the same whether booked through their own site or a distribution channel such as lastminute.com or expedia. Meta-sites will therefore commoditise many tourism products and offerings.

5. In 2006, the travel agent will have completely lost their added value as the travel expert, as the consumers themselves become more knowledgeable. Consumers are building their own content management systems. We shall see more of mytravel guide.com, myscotland.com and ianyeomans-adventures.com.

4. Pricing strategies in 2006 will be based on mark-up and services rather than on commission in the travel business.

3. Consumers in 2006 will want less choice and simplicity, rather than more choice and complexity. They want the travel world to make life simpler for them.

2. Luxury, rather than commoditisation, is the key for revenue growth in 2006.

1. Football (soccer) agents will be a thing of the past, as FIFA will launch an online football transfer system in 2006 (if only).

Happy New Year!

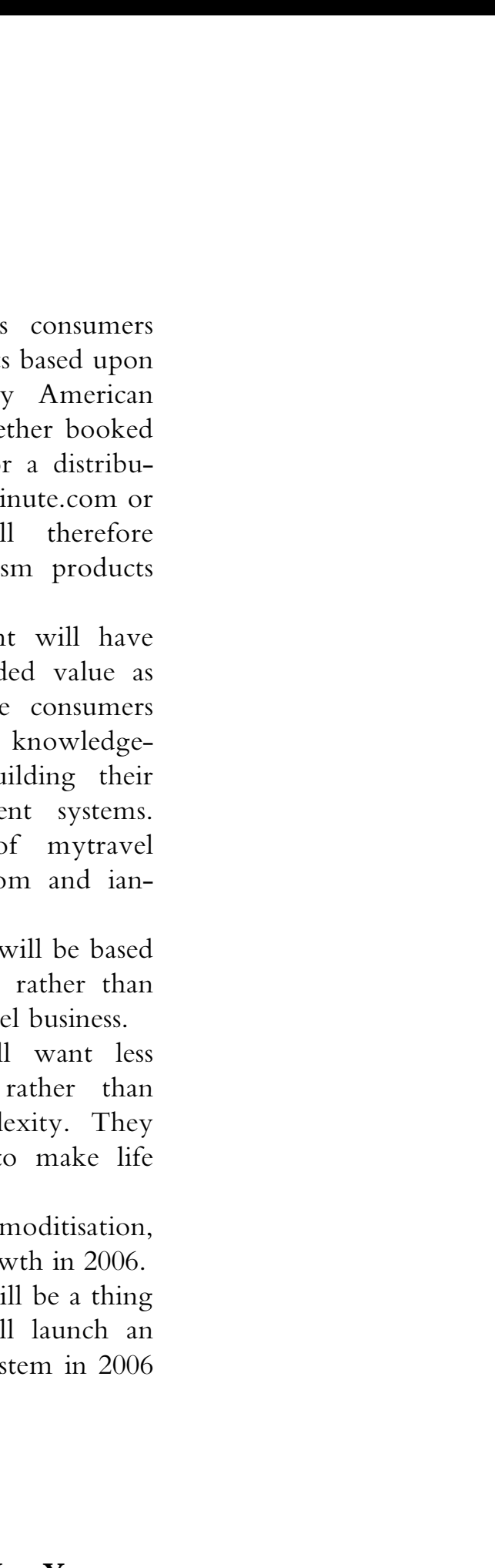

Ian Yeoman

Editor 